\title{
OS FINS DA UNIVERSIDADE: \\ HERANÇA E IMAGINAÇÃO
}

THE END OF THE UNIVERSITY:

INHERITANCE AND IMAGINATION

Mariana Ruggieri

ORCID 0000-0001-7867-6404

Universidade Estadual de Campinas,

Campinas, SP, Brasil

\section{Resumo}

Tendo como alicerce teórico o texto "As pupilas da universidade", de Jacques Derrida, o presente ensaio busca discutir a universidade a partir do ensaio Three Guineas, de Virginia Woolf, e da novela Amuleto, de Roberto Bolańo, de modo a investigar as possibilidades para um modo criativo de se herdar uma ideia.

Palavras-chave: Bolaño, Derrida, Woolf, Universidade.

Abstract

Taking Jacques Derrida’s “The Principle of Reason: The University in the Eyes of Its Pupils" as a theoretical starting point, this paper aims to debate the notion of university based on Virginia Woolf's Three Guineas and Roberto Bolaño's Amulet, in order to investigate possibilities for creatively inheriting an idea.

Keywords: Bolaño, Derrida, Woolf, University.

\section{Resumen}

El presente ensayo busca discutir la universidad a partir del ensayo Three Guineas, de Virginia Woolf, y de la novela Amuleto, de Roberto Bolaño, con base teórica en el texto "As pupilas da universidade", de Jacques Derrida, para investigar las posibilidades de un modo creativo de heredar una idea.

Palabras claves: Bolaño, Derrida, Woolf, Universidad. 
Querida, no es el Paraiso. En las calles hay batallas campales [después de las diez de la noche. Aunque la comida que preparo aún [no es del todo mala.

¿Cómo se llama esto?, pregunté. Océano. Una larga y lenta Universidad.

Roberto Bolaño

Como falar do fim se estamos mal começando? E como começar sem ter em vista algum fim? Em um texto também escrito para ser lido diante de uma plateia ${ }^{1}$ chamado "As pupilas da universidade", Jacques Derrida vai fazer uma provocante advertência:

Cuidado com o que abre a Universidade para o exterior e para o sem-fundo, mas cuidado também com o que, fechando-a em si mesma, não criaria senão um fantasma de cercado, a colocaria à mercê de qualquer interesse ou a tornaria perfeitamente inútil. Cuidado com os fins, mas o que seria uma Universidade sem fins? (DERRIDA, 1999, p.155)².

O interesse do filósofo franco-argelino é investigar o princípio da razão sobre a qual se funda a universidade e avançar a hipótese de que defender este princípio, isto é, defender a universidade, seria questionar os seus próprios fundamentos. Até onde ele sabe, diz, nunca se fundou uma universidade contra a razão, o que permite a suposição razoável de que a razão de ser da universidade sempre foi a razão, ou alguma relação essencial entre razão e ser. Mas se responder ao apelo do princípio de razão é dar a razão, explicar racionalmente os efeitos pelas causas, responder pelo princípio de razão, por outro lado, e, portanto, pela universidade, responder por esse apelo, interrogarse a respeito da origem ou do fundamento desse princípio do fundamento, não é simplesmente obedecer a ele ou responder perante ele:

1 Esse texto foi escrito para ser apresentado no evento Pesquisa e Catástrofe: I Seminário de Pesquisadores de Pós-Doutorado em Teoria e História Literária, no IEL-Unicamp, entre os dias 11 e 12 de novembro de 2019.

2 Realizei pequenas modificações nas traduções onde julguei necessário. 
Estamos obedecendo o princípio da razão quando perguntamos o que fundamenta esse princípio que é em si mesmo um princípio de fundamento? Não estamos - o que não quer dizer, por outro lado, que o estejamos desobedecendo. Estamos lidando aqui com um círculo ou com um abismo? (DERRIDA, 1999, p.134).

Não posso deixar de evidenciar o elemento central do título de sua palestra: as pupilas da universidade, ou, para ficar mais perto do título em inglês, a universidade nos olhos de suas pupilas. Resgatando a imagem da luz como veículo da razão universitária, o motivo um tanto desacreditado da iluminação civilizacional contra o mundo traiçoeiro das sombras, o que se focaliza são as pupilas, isto é, aquelas que variam seus contornos para controlar a passagem de luz. Um outro modo para dizer alunas, as pupilas modulam o apelo à razão, de modo que a instituição - a emissária da luz - importa somente na medida em que pode vir a ser filtrada com um simples piscar de olhos.

Falando na Universidade de Cornell, em Ithaca, nos Estados Unidos, uma universidade famosa pelos seus desfiladeiros, pelas suas gargantas, Derrida está interessado em uma questão que passa pela arquitetura e pela topografia, a questão da relação entre a razão e o abismo. Em um breve passeio pela história da construção do campus, ele menciona as discussóes em torno da implementação de cercados ao redor dos desfiladeiros como medidas de segurança contra ideaçôes suicidas. O seu fundador, Ezra Cornell, é citado como tendo associado a vista dos desfiladeiros à morte, relação que é explorada por Derrida para desestabilizar a noçáo de que a razão sempre estaria do lado da vida, mas também para avançar uma teoria da universidade que a obriga a conviver com o próprio abismo. "Qual é a vista, quais são as vistas da Universidade?", ele pergunta, "o que se vê desde a Universidade?" (DERRIDA, 1999, p.124). Pensar a respeito da universidade significa pensar acerca da topopolítica de um ponto de vista, o ponto de vista da universidade, o ponto de vista desde a universidade: "O que pode ser o diafragma da Universidade? Será a Universidade mestre de seu próprio diafragma? O que pode o corpo da Universidade ver ou não de sua própria destinação, daquilo em cuja vista delimita o seu chão?" (DERRIDA, 1999, p.127-128).

O que me mobiliza aqui hoje é a possibilidade de falar desde a universidade com alguma vitalidade, que, se não é exatamente uma alegria, seguramente não se trata de recostar-se contra o muro das lamentações e nutrir-se de cinismo, ressentimento e rancor. Talvez, de modo a sintetizar o que me preocupa hoje na universidade, a pergunta que fica é: como defender a universidade hoje de um fim catastrófico sem mobilizar os ideais modernos da ilustração excludente nem o fim utilitário do desenvolvimento nacional, também excludente? Ainda, se qualquer defesa da universidade mobilizará, 
inevitavelmente, alguma versão de um destino emancipatório, não seria possível vislumbrar algum fim, como se a dizer: um outro fim de mundo é possível?

Virginia Woolf, no seu longo ensaio Three Guineas, coloca uma outra variação desse conjunto de perguntas. O livro, publicado em 1938, quando a Alemanha nazista engolia a Tchecoslováquia, é uma longa resposta a uma carta fictícia, na verdade a três cartas, mas disparada pela pergunta contida na primeira: "como a guerra pode ser evitada?" (p.9). O remetente sugeria que ela assinasse um manifesto para "proteger a cultura e a liberdade intelectual" (p.95). Woolf vai se recusar a assinar o manifesto, não porque ela fosse a favor da guerra, evidentemente, ou pensasse que a guerra fosse inevitável, mas porque não estava tão claro o que estava implícito por "cultura" e "liberdade", sugerindo, entáo, que, antes de propor um manifesto, ele investigasse a sua relação com a manutenção de um sistema educacional patriarcal e, portanto, bélico. De modo provocativo, a resposta às cartas ousava propor a outras mulheres que elas não se aliassem a seus pais e irmãos, esses "homens instruídos" que urgiam às mulheres o empenho na proteção de um mundo construído para e por eles:

É imprescindível que pensemos (...) Náo paremos nunca de pensar - em que consiste esta "civilização" em que nos encontramos? Em que consistem essas cerimônias e por que devemos participar delas? Em que consiste esta "civilizaçáo" em que nos encontramos? Em que consistem essas cerimônias e por que devemos participar delas? Em que consistem essas profissóes e por que devemos ganhar dinheiro exercendo-as? Para onde, em suma, ela está nos levando, essa procissão dos filhos dos homens instruídos? (WOOLF, 2019, p.73).

O centro da discussão nessa parte do ensaio é a formação universitária em um momento em que as mulheres das "classes instruídas" iam pouco a pouco ganhando acesso a ela. A discussão gira em torno da exclusão fundante da universidade, um espaço exclusivamente masculino, e os modos de inclusão das mulheres nessa procissão que já está em andamento, a despeito delas. É o modo de inclusão, precisamente, que faz emergir o comando: "É imprescindível que pensemos [ Think we must]". "Queremos nos juntar àquela procissão ou não queremos? Em que termos devemos nos juntar àquela procissão? Sobretudo, para onde ela está nos levando, a procissão dos homens instruídos?” (WOOLF, 2019, p.71). Em sua resposta, Woolf é assertiva com o seu remetente, um homem da mesma classe social, com o mesmo sotaque, a mesma etiqueta nos longos jantares que frequentam, mas com uma diferença notável - um precipício, ela diz - em relação às possibilidades de acessar a educação e o mundo. As mulheres das classes abastadas ficam em casa onde recebem aulas 
particulares de alemão e piano, enquanto os seus irmãos vão à universidade e viajam o mundo com os fundos constituído pelas ricas famílias inglesas desde o século XIII, disparidade que também havia subsidiado todo o desenvolvimento argumentativo em Um teto todo seu, publicado em 1929. Tecendo relaçóes convincentes entre a guerra, a tradição, a universidade e o patriarcado, Woolf busca delinear um modo de pensar uma instituição universitária fundamentada sobre outros pressupostos. Em um momento posterior do texto, dirigindo-se à tesoureira de uma organização que pede uma doação para a reconstrução de uma faculdade para mulheres, ela escreve:

Ora, uma vez que a história e a biografia - a única evidência disponível para quem é uma outsider - parecem provar que a antiga educação das faculdades não produz nem respeito especial pela liberdade nem aversão particular à guerra, fica claro que vocês devem reconstruir a sua faculdade de maneira diferente. Ela é jovem e pobre; deixem, portanto, que ela tire vantagem dessas características e seja alicerçada na pobreza e na juventude. Obviamente, ela deve ser, portanto, uma faculdade experimental, uma faculdade ousada. Que seja construída de acordo com diretrizes próprias. (...) Deve ensinar as artes das relaçóes humanas; a arte de compreender a vida e a mente dos outros povos, e as pequenas artes da conversação, do vestir-se, da culinária que a elas estáo associadas. $\mathrm{O}$ objetivo da nova faculdade, a faculdade barata, não deve ser segregar e especializar, mas combinar. (WOOLF, 2019, p. 42-43).

Woolf, sabe, no entanto, das dificuldades de implementar uma universidade fundamentada sobre esses princípios, entende a necessidade de formar mulheres aptas a obter o próprio sustento, pondera que, naquele momento, somente uma universidade orientada ao mercado de trabalho pode retirar as mulheres da obrigatoriedade do casamento, de modo que ela aceita realizar a doação de um guinéu, alertando, porém, para a inevitabilidade de um futuro reincidente:

E uma vez que essa realidade significava que ela deveria reconstruir sua faculdade na mesma linha que as outras, concluía-se que a faculdade destinada às filhas dos homens instruídos também deveria fazer com que a pesquisa produzisse resultados práticos que atraíssem legados e doaçóes por parte dos homens ricos; deveria estimular a competição; deveria aceitar a concessão de graus acadêmicos e o uso de capelos coloridos; deveria acumular uma grande riqueza; deveria excluir outras pessoas da partilha de sua riqueza; e, portanto, em quinhentos anos, mais ou menos, essa faculdade também deveria fazer a mesma pergunta que o senhor está fazendo agora: "Como, em sua opiniáo, conseguiremos evitar a guerra?” (WOOLF, 2019, p. 44). 
O ensaio de Woolf, claro, não pode ser tomado como um programa político e tampouco sustenta toda sua argumentação em torno da relação entre guerra e patriarcado. A força de seu texto, porém, vem muito menos de uma precisão teórica em torno do que hoje chamamos de teoria de gênero do que de sua habilidade de questionar, a partir da desigualdade entre gêneros, os fundamentos da pergunta que lhe é feita. A partir dessa recusa a uma mobilização amnésica, Isabelle Stengers e Vinciane Despret publicaram em 2011 um livro coletivo, Les faiseuses d'histoires: que font les femmes à la pensée?, onde nove professoras-pesquisadoras são convidadas a responderem a uma pergunta que tem como eixo de partida o "think we must!", de Woolf. Seria possível dizer, segundo as filósofas, que esse imperativo de Virginia Woolf é uma proposição elitista, dirigida, como foi, somente às filhas e irmãs de homens ricos e bem-formados, "mas nós a vivenciamos em outra chave: de modo que ela se torne inseparável da criação de uma memória que pode ser uma fonte de resistência”. (DESPRET \& STENGERS, 2011, p. 32) 3 . A ideia é propor uma reflexão sobre o substrato universitário; não apenas o substrato sobre o qual se pensa, mas principalmente o substrato por meio do qual se pensa. Se a universidade não é um lugar qualquer, elas parecem dizer, é preciso induzir uma transformação a partir da constituição criativa e fabulativa de uma memória coletiva, sem nenhuma inocência:

Nós não sabemos se é possível salvar essa universidade deplorável cuja passividade nós entendemos melhor, graças a Woolf. As "fronteiras místicas", as ideias abstratas podem gerar alguns resmungos, até mesmo algumas resistências individuais, mas não a habilidade coletiva de agir de outro modo. (DESPRET; STENGERS, 2011, p.55).

Se há hoje, na universidade, alguma dimensão de tristeza - uma sensação de derrota individual e coletiva, cortes e mais cortes de verbas -, é preciso politizá-la em nome da possibilidade de alguma movimentação teórica conjunta. Não de modo narcísico, visando o gozo imediato diante da própria brilhanteza, mas ativamente orientando-se em grupo dentro de um modo fabulatório que possibilite trazer à tona os recursos imaginativos - e modos de demandar os recursos financeiros - que não desembocarão na sensação onipresente de impotência. $\mathrm{O}$ que não quer dizer que o desejo náo seja uma parte fundamental do processo de inventar e de proliferar essas fabulaçóes: é a ausência de prazer e de invenção que também ratifica o caráter inabitável do nosso mundo. Para Stengers e Despret, responder ao chamado do "Think we must!" trata-se, sobretudo, em primeiro lugar, de redeterminar

3 Todas as traduções de Despret \& Stengers são minhas. 
coletivamente os termos da pergunta, mais do que juntar-se à procissão de respostas especialistas que agem sob a prerrogativa de conterem soluçóes.

O subtítulo da tradução do livro de Stengers e Despret ao inglês, Women who make a fuss, de 2014, é: "the unfaithful daughters of Virginia Woolf”. Há aqui um duplo sentido que se complementa: as filhas infiéis de Virginia Woolf, isto é, infiéis, juntas, às instituiçóes, mas também - por outro lado e ao mesmo tempo - as filhas infiéis de Virginia Woolf, isto é, infiéis a ela, a mãe. Desse modo, a questão passa a ser sobre a herança e os seus modos, sobre o modo de herdar ideias e instituiçóes, porque em grande medida náo se trata de começar do zero, mas de começar de novo. A premissa colocada por elas é de que herdamos um problema chamado universidade e o que precisa ser feito, então, é buscar a reconfiguração do problema. Como método de demonstração, escolhem uma fábula beduína sobre um velho sábio e seus camelos: um homem, ao morrer, deixou de herança aos três filhos onze camelos, que deveriam ser divididos em uma conta impossível - metade dos bens para o mais velho, um quarto para o do meio e um sexto para o caçula. $\mathrm{Na}$ iminência de haver guerra entre eles, consultam um sábio, que diz que não pode fazer nada por eles, exceto lhes dar o seu único camelo, velho e magro. Agora com doze camelos, os filhos conseguem efetuar a divisão: seis para o mais velho, três para o do meio e dois para o caçula. Devolvem, entáo, ao sábio o camelo velho. O que parece ser relevante para Stengers e Despret nessa história é a possibilidade de construir uma versão da herança a partir de uma intervenção inesperada, um dispositivo que vai e volta; o camelo do sábio é uma tecnologia da partilha. Trata-se menos de propor uma tábula rasa, e mais de rearranjar os termos da equação. As autoras, então, especulam sobre aquilo que teria a força desse camelo suplementar na reconfiguração dos nossos dias, concluindo que:

Não cabe aos filósofos oferecerem o camelo suplementar da sua época, como o homem sábio da fábula - filósofos não são pessoas sábias e, além disso, ninguém vem consultá-los. No lugar disso, pensamos que o camelo pertence à própria época, no modo daquilo que é capaz de vir a ser. Não somos heroínas do pensamento, enfrentando sentimentos estabelecidos, mas especuladoras do possível, dependendo das possibilidades de pensamento que pertencem ao presente. (DESPRET; STENGERS, 2011, p. 76).

Não aparece, entretanto, na fórmula do camelo a possibilidade de se questionar os termos da divisão, fato que também parece não importar muito a Stengers e Despret, talvez porque uma divisão igualitária impedisse a devoluçáo do camelo suplementar, reconfigurando a própria noção de herança - e da lei. A matemática da herança dos camelos, então, talvez não sirva tanto para pensar a universidade, ou soe excessivamente estranha em um país onde a 
universidade é, ainda hoje, em muitos sentidos, uma questáo hereditária de concentração de renda - e às vezes de filiação teórica. Ou talvez o problema não seja a herança - o ato de herdar -, mas os camelos, pois há sempre a possibilidade de herdar a universidade e as diversas linhas de pensamento como se herda uma língua, em que a própria herança já a torna mais viva, mais variada, mais barulhenta. A herança em forma de memória, mais do que em forma inventariável, produz a possibilidade de posicionar-se diante dos termos colocados. Nessa nova versão da fábula, nenhum elemento suplementar seria necessário, pois estaria já contido na própria coisa herdada, como uma espécie de fissura constitutiva, demandando a reconfiguração do problema.

A obra de Roberto Bolaño é assombrada pelo espectro da Universidade Desconhecida. Essa imagem aparece dispersamente em diversos poemas, além de aparecer em 2666 brevemente mencionada na anotação do diário de um dos personagens, em uma espécie de exercício de associação livre diante de um quadro de Courbet. O quadro, Les Demoiselles des bords de la Seine (eté), exposto no Salão de Paris em 1857, causou um grande escândalo à aristocracia francês, acusado de vulgaridade. Proudhon, por outro lado, amigo de Courbet, considerava que era uma denúncia à moral do regime: a mulher dormindo estaria se entregando a fantasias eróticas, ao passo que a outra estaria obsessionando em torno de suas finanças. No livro de Bolaño, o quadro é descrito simplesmente como o breve descanso dos espióes ou dos náufragos. Nesse fluxo imagético e político, indaga-se à universidade desconhecida sobre o ensino da resistência, ou sobre a própria possibilidade de se ensinar algo como a resistência: "disposición a resistir, y también: dónde se aprende a resistir?, en qué clase de escuela o de universidad?, y también: fábricas, calles desoladas, burdeles, cárceles, y también: la Universidad Desconocida" (BOLAÑO, 2004, p. 913). De modo geral, a Universidade Desconhecida surge na obra do chileno como um lugar que não se materializa espacialmente, mas por meio da qual se obtém uma formação literária extracanônica, formação ligada sobretudo, para Bolańo, às noçóes de coragem e valentia. Em dois poemas onde isso fica mais claro, reunidos em uma extensa antologia intitulada La Universidad Desconocida, a Universidade Desconhecida emerge com a força de um respiro, um contraponto: "Esta esperanza yo no la he buscado. Este pabellón silencioso de la Universidad Desconocida" ou "Querido Alfred Bester ${ }^{4}$, ipor lo menos / he encontrado uno de los pabellones

4 Alfred Bester é autor do conto de ficção científica "The Men who Murdered Mohammed", no qual o personagem principal é professor da Universidade Desconhecida. No conto, a universidade também se mantém envolta em mistério; diz-se que ninguém sabe onde ela fica ou o que se ensina nela. 
I de la Universidad Desconocida!". (BOLAÑO, 2007) Em outro poema, chamado Atole, uma bebida matinal de notívagos e trabalhadores braçais, a monumentalização de seus amigos, os poetas Mario Santiago e Orlando Guillén provocam a memória de seus sorrisos vivos e livres quando ainda podiam, segundo diz, aparecer e desaparecer como a poesia verdadeira. Ele os vê expostos: "En los murales de una nueva universidad / llamada infierno o algo que podía ser / una especie de infierno pedagógico" (BOLAÑO, 2007). Aqui, a universidade é nova, o que náo é de qualquer maneira a mesma coisa que ser desconhecida. A novidade estaria marcada por um gesto fundacional, sem nenhuma relação, ainda que transgressora, com algo como a tradição, dentro da qual a pedagogia infernal surge como um regime de significado já dado de antemão. Em El espíritu de la ciencia-ficción, novela experimental de 1984 publicada postumamente em 2016, a Universidade Desconhecida aparece como uma espécie de pano de fundo, embora isso não esclareça muito sobre o seu funcionamento. Quando um personagem é indagado por outro acerca da definiçáo de tal universidade, responde pela via tautológica: "Una universidad que nadie conoce, por supuesto". (BOLAÑO, 2016, p. 101). O mesmo personagem, que atua na novela como um duplo de Roberto Bolaño e tem como hábito escrever a seus escritores preferidos, vivos, de ficção científca, conta que escreveu a Ursula Le Guin, escreve sobre "los sueños y la Revolución". O amigo lhe pergunta se escreve também sobre a universidade desconhecida, e também: “¿Por qué no le preguntas si sabe dónde se encuentra?" (BOLAÑO, 2016, p. 103). A Universidade Desconhecida aponta para um lugar ou uma ideia partilhada pelos especuladores do futuro, os ficcionistas da ciência, os viajantes do tempo.

É interessante, portanto, que em meio a uma obra assombrada pelo horizonte utópico de uma universidade inalcançável surja uma novela como Amuleto, onde a universidade aparece materializada em uma instituição existente, mais precisamente na UNAM - uma das maiores universidade do mundo - no ano de 1968. Aqui, a injunção temporal das alucinaçóes ou sonhos da personagem principal, Auxilio Lacoutoure, promove certa viagem no tempo, ainda que não de modo linear. A novela começa com um aviso dado por ela: "Esta será una historia de terror. Será una historia policíaca, un relato de serie negra y de terror. Pero no lo parecerá. No lo parecerá porque soy yo la que lo cuenta. Soy yo la que habla y por eso no lo parecerá. Pero en el fondo es la historia de un crimen atroz". (BOLAÑO, 2013, p. 11). Auxilio Lacouture fica mais de 15 dias presa no banheiro da UNAM quando esta é invadida pelo exército em setembro de 1968, algumas semanas antes do massacre de Tlatelolco. Durante esses dias, ela sofre uma série de alucinações, que a tese de Geruza Zelnys (2014) afirma serem frutos de um relato dado sob tortura. As primeiras frases do livro corroboram essa possibilidade, assim 
como o momento, durante uma das alucinaçóes, em que Auxilio é levada por médicos para assistir ao parto da História. Em um cenário hospitalar, ela é anestesiada. Segundo seu relato: "Fijaba mi vista en el techo y sólo oía el traqueteo de goma de la camilla y los gritos en sordina de otros enfermos, de otras víctimas del pentotal sódico (eso pensaba), y hasta sentía un ligero calorcillo confortable que subía lentamente por mis largos huesos helados" (BOLAÑO, 2013, p. 129). O pentotal sódico é um dos muitos compostos químicos que baixam a guarda da consciência, tornando-o matéria prima para aquilo que se conhece como "soro da verdade".

Mas Amuleto não trará nenhuma confissão e sua história tampouco se configurará como uma narrativa de testemunho, no sentido clássico de evidenciar a catástrofe. A confusão temporal do relato, em que passado, presente e futuro não estấo ordenados de modo cronológico, antes comparecendo juntos ao banheiro da universidade em que Auxilio está presa - refém indireta da invasão militar -, oferecerá alguns fragmentos de futuro a partir dos abismos do passado. A hipótese da crítica Susana Draper (2012) é de que a memória política de Auxilio Lacouture tem como particularidade a imaginação obsessiva com "encuentros que nunca sucedieron". A possibilidade de imaginar o nãosido, isto é, o que poderia ter sido, é o que permite pensar também naquilo que pode vir a ser. Por isso ela poderá sobreviver à tomada militar do Campus Universitário. Em 1968, os estudantes estavam mobilizados desde o início do ano em defesa da autonomia universitária, contra a invasão de uma das escolas preparatórias. (Náo esquecer que simultaneamente transcorria, na França, uma luta contra a universidade napoleônica.) Ano também das Olimpíadas, o governo federal de um México supostamente democrático, ainda que seguisse há décadas com o mesmo partido no poder, agiu com violência para reprimir as manifestaçóes iniciais que foram, portanto, aumentando. $\mathrm{O}$ campus da UNAM é tomado pelo exército por mais de 10 mil soldados, e as mobilizaçôes são por fim esmagadas em 2 de Outubro, na praça de Tlatelolco, com o assassinato de 400 pessoas, em sua grande maioria estudantes, tragédia que foi transformada por Elena Poniatowska em um livro do testemunho das muitas vozes sobreviventes.

Em Amuleto não há muito o que ser visto ou testemunhado em sentido estrito; presa em um banheiro em um campus vazio, Auxilio desvia seu foco de observação para o tempo em sua longa duração, suas visōes são atravessadas por prospecçóes acerca do futuro (de onde surgirá o ano de 2666, que dará título à mais extensa obra de Bolaño) e reimaginaçóes do passado. Desviando o foco do 68 mexicano para longe do local do massacre, o livro opera nos interstícios menores da história, articulando todo o horror que neles existe com as possibilidades de centelhas de uma história distinta. O desvio testemunhal é operado mais uma vez ao escolher como a última 
trincheira da universidade o banheiro, o refugo tornado refúgio, um lugar inespecífico à universidade, em vez de um lugar que a caracterizaria em sua particularidade e institucionalidade, como uma sala de aula, os salóes nobres ou as salas dos professores. Não é menos significativo que quem tenha ficado ali como única civil não fosse estudante nem professora, mas alguém que frequentasse a universidade pelas beiradas, fazendo bicos, assistindo aulas, sem estar matriculada, sem também ser mexicana, porque era imigrante uruguaia sem papéis. Nos intervalos de suas viagens temporais, sempre que o banheiro sitiado se materializa como realidade incontornável, Auxilio expressa a sua permanência ali como um gesto de defesa da autonomia universitária. De fato, do modo como Auxilio conta a história, a autonomia universitária existia, naquele momento, apenas ali com ela: "me disponía moral y físicamente, llegado el caso, a no abrir, a defender el último reducto de autonomía de la UNAM, yo, una pobre poetisa uruguaya”. (BOLAÑO, 2013, p. 33). Em outro momento, em um sonho com Remedios Varo, a pintora espanhola que viveu exilada do franquismo no México, ela escuta: "no te preocupes, Auxilio, no te vas a morir, no te vas a volver loca, tú estás manteniendo el estandarte de la autonomía universitaria, tú estás salvando el honor de las universidades de nuestra América, (...) lo peor que te puede pasar es que tengas visiones (...)". (BOLAÑO, 2013, p. 97).

Essas visóes vão possibilitando uma série de encontros, como se Auxilio presa no banheiro do $4^{\circ}$ andar da Faculdade de Filosofia e Letras pudesse configurar a autonomia universitária, dar a ela certo contorno dentro do campus militarizado, por se transmutar em uma espécie de antena. Captando sinais de outros tempos, pregressos e futuros, e retransmitindo-os, suas visóes vão aos poucos gerando uma aglomeração de pessoas: poetas mortos e poetas jovens, poetas exilados, poetas pobres: "como se com a ajuda de um novo dispositivo óptico fosse possível finalmente ver a vista, não apenas a paisagem natural, a cidade, a ponte e o abismo, mas fosse possível ver a visáo.", para voltar a Derrida, ainda falando lá em Cornell sobre as pupilas. "Como se por meio de um dispositivo acústico fosse possível ouvir a audição, em outras palavras, capturar o inaudível em uma espécie de telefonia poética". (DERRIDA, 1999, p. 156). Ver o ato de ver, a condição da reflexão para Derrida, o "think we must!", de Virginia Woolf, mas também das visões de Auxilio, que, não compondo oficialmente nenhum dos corpos da universidade - nem corpo docente, nem corpo discente -, se viu ali defendendo a autonomia universitária, e o fez olhando de novo pra fora, como se o seu corpo ali servisse para atar o elo entre os polos dentro e fora da universidade em uma América Latina atravessada por lutas. Auxilio relata: "Yo me dispuse a resistir. A resistir el hambre y la soledad. (...) Yo tuve sueños, no pesadillas, sueños musicales, sueńos de preguntas transparentes, sueños de aviones esbeltos y seguros que 
cruzaban Latinoamérica de punta a punta por un brillante y frío cielo azul". (BOLAÑO, 2013, p. 144-145).

Um encontro impossível, por exemplo, entre Darío e Huidobro coloca a questão da possibilidade de imaginar uma outra vanguarda. A história da poesia latino-americana teria sido outra, diz Auxilio,

Porque, digo yo, Darío le habría enseñado mucho a Huidobro, pero Huidobro también le habría enseńado cosas a Darío. La relación entre el maestro y el discípulo es así: aprende el discípulo y también aprende el maestro. Y puestos a suponer, yo creo, y Pacheco también lo creía (...) que Darío hubiera aprendido más, y hubiera sido capaz de poner fin al modernismo e iniciar algo nuevo que no hubiera sido la vanguardia pero sí una cosa cercana a la vanguardia, digamos una isla entre el modernismo y la vanguardia, una isla que ahora llamamos la isla inexistente, palabras que jamás fueron, y que sólo pudieron ser (y ya es mucho suponer) tras el encuentro imaginario entre Darío y Huidobro, y el propio Huidobro tras su fructífero encuentro con Darío hubiera sido capaz de fundar una vanguardia más vigorosa aún, una vanguardia que ahora llamamos la vanguardia inexistente y que de haber existido nos hubiera hecho distintos, nos hubiera cambiado la vida. (BOLAÑO, 2013, p. 57).

Mas não seria outra apenas a história da poesia; na história da vanguarda latino-americana, nessa possibilidade de imaginar vínculos que não existiram, está a própria vida. Contida nessa ideia de um embaralhamento temporal que pode nos contar coisas que náo sabemos sobre o nosso passado e sobre a possibilidade de futuro, está também colocada a possibilidade de redefinir a natureza das relaçóes pedagógicas. No último fragmento do Rua de mão única, de Walter Benjamin, chamado "Ao Planetário", o tema é o enfraquecimento da experiência com o advento dos Luna Parks e a dominaçáo da natureza pela técnica. Dentro dessa reflexão, Benjamin acena brevemente para a relação entre mestre e aluno, que seria indício da real relação entre natureza e técnica: "Não é a educação, antes de tudo, a indispensável ordenação da relação entre as geraçóes, e, portanto, se se quer falar de dominação, a dominação das relações entre gerações, e não das crianças?”. (BENJAMIN, 1987, p. 69). Auxilio parece defender a autonomia universitária na medida em que configura esse espaço de trânsito intergeracional, mas buscando um ordenamento distinto, ligeiramente deslocado.

Talvez por isso para Susana Draper o encontro entre Auxilio e a pintora surrealista Remedios Varos, exilada do franquismo no México, seja ainda mais interessante. Com ele passamos do encontro impossível entre dois poetas que nomeiam o modernismo e a vanguarda, o télos da historicização literária, o lugar universitário por excelência, a um encontro também impossível (Varos havia falecido em 1963) entre duas mulheres que colocam questôes à noção 
de "fraternidade, liberdade, igualdade", de modo a aprofundar a possibilidade de uma universidade desconhecida.

(...) alguien abre la puerta y es Remedios Varo (...) dice que ya no fuma, que sus pulmones ahora son débiles, aunque no tiene cara de tener los pulmones malos, ni siquiera tiene cara de haber visto algo malo, aunque yo sé que ella ha visto muchas cosas malas, la ascensión del diablo, el inacabable cortejo de termitas por el Árbol de la vida, la contienda entre la Ilustración y la Sombra o el Imperio o el Reino del Orden, que de todas esas maneras puede y debe ser llamada la mancha irracional que pretende convertirnos en bestias o en robots y que lucha contra la Ilustración desde el principio de los tiempos (conjeturación mía que ningún ilustrado daría por buena), yo sé que ella ha visto cosas que muy pocas mujeres saben que han visto (...) Es hora de irme. No sé si darle la mano o darle un beso en cada mejilla. Las latinoamericanas, hasta donde sé, sólo damos un beso. Un beso en una mejilla. Las espańolas dan dos. Las francesas dan tres. Cuando yo era jovencita pensaba que los tres besos que daban las francesas querían decir: libertad, igualdad, fraternidad. Ahora sé que no, pero me sigue gustando pensarlo. Así que le doy tres besos y ella me mira como si también, en algún momento de su vida, hubiera creído lo mismo que yo. Un beso en la mejilla izquierda, otro en la derecha, un último beso en la mejilla izquierda. Y Remedios Varo me mira y su mirada dice: no te preocupes, Auxilio, no te vas a morir, no te vas a volver loca, tú estás manteniendo el estandarte de la autonomía universitaria, tu estás salvando el honor de la universidad de nuestra América (...). (BOLAÑO, 2013, p. 92-97).

Nessa longa passagem surgem, quase que sintetizadas, os problemas que o livro elabora desde esse olhar não-simétrico, operando as tensôes entre o projeto ilustrado, a razão, o legado emancipatório da Revolução Francesa, seu mote e a defesa da autonomia universitária. A despedida, os três beijos, se coloca com uma espécie de dívida em relação à promessa emancipatória "liberdade, igualdade e fraternidade", mas exposta agora desde uma fraternidade impossível (entre irmãs que sabem o que viram) que habita os limiares indefinidos entre a razão ilustrada e a mancha de uma ordem irracional. Esse encontro descentraliza a fraternidade histórica e abre caminho para uma forma outra de fraternidade, cujo conceito retoma a memória do desejo e a importância dos vínculos afetivos e políticos, fazendo pensar nas possibilidades vivas das palavras já gastas pela história: fraternidade, igualdade, liberdade, vanguarda, universidade. Vivendo e olhando desde as bordas, a sua possibilidade de resistir e defender - isto é, a possibilidade de reler e, portanto, de reescrever - passa por não viver o mito fundador da inteireza original ${ }^{5}$, um

5 Aqui estou retomando a formulaçáo de Gloria Anzaldúa a respeito de Malinche, a intérprete de Hernán Cortés, eternizada historicamente como a figura da traidora, e que na leitura de Anzaldúa é a grande sobrevivente da colonização, tendo caminhado entre línguas para sobreviver. 
fundamento, portanto, que está, como a universidade de Derrida, "suspenso sobre um vazio muito particular".

O final do livro, em que Auxilio vê uma procissão de fantasmas caminhando rumo ao abismo, postula um modo de conviver com ele, com essa ferida aberta, não como destinação, nem como derrota. As ruínas são interessantes não pelas ruínas, mas pelos caminhos que se abrem.

Supe también que pese a caminar juntos no constituían lo que comúnmente se llama una masa: sus destinos no estaban imbricados en una idea común. Los unía sólo su generosidad y su valentía (...) Caminaban hacia el abismo (...) Y los oí cantar, los oigo cantar todavía, ahora que ya no estoy en el valle, muy bajito, apenas un murmullo casi inaudible, a los niños más lindos de Latinoamérica, a los ninốs mal alimentados y a los bien alimentados, a los que lo tuvieron todo y a los que no tuvieron nada (...) Lo único que pude hacer fue ponerme de pie, temblorosa, y escuchar hasta el último suspiro su canto, escuchar siempre su canto, porque aunque a ellos se los tragó el abismo el canto siguió en el aire del valle, en la neblina del valle que al atardecer subía hacia los faldeos y hacia los riscos. (BOLAÑO, 2013, p. 152-153).

Esse canto, o livro nos vai dizer em sua última linha, é o nosso amuleto. A força da imagem do amuleto está na proteção que ele oferece, o que é bastante diferente da possibilidade de uma solução mágica. Sozinho ele não pode nada. Náo se pode segurar um amuleto entre as máos enquanto se tenta não afogar: o amuleto fica preso ao corpo, deixando as mãos livres para trabalhar. Pensar a universidade, o campus, as alturas e as barreiras contra o abismo, mas sempre que necessário, diria Derrida, mobilizar o pensamento mais diretamente subterrâneo sobre o abismo debaixo da universidade. 
Referências

BENJAMIN, Walter. Rua de mão única - Obras escolhidas, Volume II. São Paulo: Editora Brasiliense, 1987.

BOLAÑO, Roberto. 2666. Barcelona: Anagrama, 2004.

BOLAÑO, Roberto. Amuleto. Barcelona: Anagrama, 2013.

BOLAÑO, Roberto. El espiritu de la ciencia-ficción. Barcelona: Anagrama, 2016.

BOLAÑO, Roberto. La Universidad Desconocida. Barcelona: Anagrama, 2007.

DERRIDA, Jacques. As pupilas da Universidade. In: $O$ olho da Universidade. São Paulo: Estação Liberdade, 1999.

DRAPER, Susana. Fragmentos de futuro en los abismos del pasado: Amuleto, 1968-1998. In: RODRÍGUEZ FREIRE, Raúl (org). Fuera de quicio: Bolaño en el tiempo de sus espectros. Santiago: Ripio Ediciones, 2012.

DESPRET, Vinciane \& STENGERS, Isabelle. Les faiseuses d'histoires: que font les femmes à la pensée? Paris: La Découverte, 2011.

WOOLF, Virginia. Três Guinéus. Belo Horizonte: Autêntica, 2019.

Mariana Ruggieri. Doutora em Teoria Literária e Literatura Comparada pela Universidade de Sáo Paulo. Atualmente realiza seu pós-doutorado na Unicamp, com financiamento da FAPESP.

E-mail: ruggieri.mari@gmail.com 